\title{
Technical Efficiency in the Small Scale Industrial Sectors of Punjab and Haryana - A Comparative Analysis
}

Satinder Kumar, Parminder Singh*

Abstract:

The present study deals with the inter-temporal variations of technical efficiency in the small scale industrial sector of Punjab and Haryana and compares the performance of both states with the small scale industrial sector of India. Data spanning over the period 1972-73 to 2006-07 has been utilized to estimate technical efficiency with the help of data envelopment analysis (DEA) based upon efficiency scores. The empirical analysis confirms that there exists 0.176 percent and 0.470 percent technical inefficiency in the small scale industrial sectors of Punjab and Haryana, respectively. However, at the aggregated All-India level, the technical inefficiency score is 0.449. Thus, the small scale industrial sector of Punjab is comparatively more efficient than that of Haryana and All-India. Moreover, the reform process has adversely affected both the managerial and scale efficiencies of Haryana, whereas an improvement in managerial efficiency has been observed in the small scale industrial sectors of Punjab and All-India. The empirical analysis showed that in the post-reform period both at the AllIndia level and in Haryana technical inefficiency scores are increasing, whereas in Punjab it is decreasing. Thus, it can be inferred that scale efficiency is an important determinant of technical efficiency in explaining the performance of the small scale industrial sectors of Punjab and Haryana.

Keywords: Small scale industrial sector, Technical efficiency, Managerial efficiency, Scale efficiency, Liberalisation

JEL: R32, R58, D61, C61, G32

DOI: $10.2478 / \mathrm{v} 10033-011-0020-0$

\section{Introduction}

The small scale industrial sector has emerged as a dynamic and vibrant sector of the Indian economy due to its contribution to achieving the socio-economic objectives of employment, production, exports, fostering entrepreneurship, contribution to Gross Domestic Product (GDP) and ensuring industrial dispersal. The small scale industrial sector (SSI's) contributes 8 per cent of the country's GDP, 45 per cent of manufactured output, and 40 per cent of exports. The labor-capital ratio in SSI is much higher than in larger industries. Moreover, SSIs are better dispersed, and are the second largest employer of human resources after the agriculture sector. (Economic Survey, 2011) The employment in this sector has increased to 29.81 million in 2009-2010 from 3.97 million in 1973-1974 (Annual Report, 2010). Due to this reason this sector was accepted as an engine of economic growth in the early years of planning and the Indian government has initiated various support measures in terms of policies on reservation, revision of investment ceilings, modernization, technological up-gradation, marketing assistance, fiscal incentives, etc., to uplift this

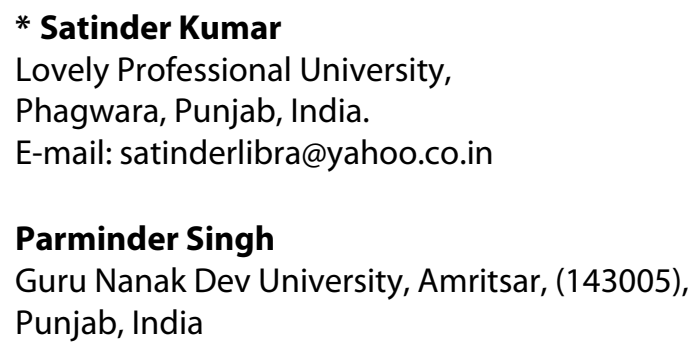


sector to enable it to play a crucial role in the process of attaining sustained and inclusive growth.

Small scale industry produces a wide range of commodities from ordinary consumer goods to sophisticated goods based on modern technology like electronic goods, television sets, engineering products, etc. Various steps have been taken by the government from time to time, such as establishing the Handloom board, Handicraft board, Cottage industry board, Khadi and Village industry board, etc. to augment the performance of the small scale industrial sector in India. Despite these efforts of the government, 77,723 units in the Indian small scale industrial sector were observed to be sick in the year 2009-10 (RBI, 2010). In the cases of Punjab and Haryana, the number of sick units during the same period was 2,236 and 1,060, respectively (Lok Sabha, 2009). This portrays the gloomy picture of the present status of the Indian small scale industrial sector. The sickness of small scale industries in India in general and Punjab and Haryana in particular occurred due to various reasons, such as the lack of entrepreneurial skills, irregular supply power and raw material, lack of skilled labor, the limited role of financial institutions, inadequate market information, global competition, changes in economic conditions, and the installation of technically defective and outdated technology.

In this context, the basic objective of the present paper is to empirically examine the inter-temporal variations of technical efficiency in the small scale industrial sector of Punjab and Haryana and compare the performance of both the states with the small scale industrial sector of India. For this purpose, the technical efficiency of the small scale industrial sector is analyzed with the help of data envelopment analysis (DEA) both at the All-India level and at a regional level.

In the realm of comparative studies, Nagaraj (1997 and 2003) and Chaudhuri (2002) observed that the growth rate in the manufacturer sector is lower in the post-reform period than in the pre-reform period. Ahluwalia (2006) found deceleration in the growth value added in the manufacturing industry at the aggregate level. Though the results are quite similar, the explanations seem to diverge- while Nagaraj (1997-2003) attributes it to the decline in the role of the government, Ahluwalia (2006) explains the deceleration in terms of the slowdown in reforms. Other studies by Goldar (1985), Little et al (1996), Bhavani (1991) and Nikaido (2004) found that technical efficiency is positively correlated with firm size. The conclusion is the same in this study even the methodology appear wander - as Goldar (1985) and Nikaido (2004) apply stochastic frontier analysis (SFA), Bhavani (1991) and Little (1996) apply a translog production function, and further Little (1996) reveals no systematic relationship between employment size and technical efficiency. However, the study of Nikaido (2004) refuted this view by finding the agglomeration of firms to positively affect the measure of technical efficiency, while firm size had a negative effect on the same.

Sivalingam (2008) and Suresh (2009) observed that significant contributions are made by the small scale industrial sector in employment generation as well as rural industrialization. Though the findings are quite similar, the suggestions seem to be different - while Sivalingam (2008) suggested the ingredients for development of SSI are infrastructure development, direct catalytic subsidy, and technical, information and marketing support, Suresh (2009) recommended cost effectiveness, improving the quality of the product, diversifying the production process and confronting challenges by enhancing competitiveness at both intraand international levels.

Singh (2008) argued that the industrial sector has lagged behind in the post-reform period. Its contribution to the gross domestic product is (GDP) remained at 16 percent throughout the study period, 1980-2002. Thus, he regarded the "impediments to internal trade, labour market rigidities, and barriers in doing business" as responsible for hampering further growth in industry.

In a recent study, Mehta (2011) found a slower trend in the growth-rate of the value added in the post-reform period in the organized manufacturing sector. Further study shows some positive signs of a structural shift within the manufacturing sector, yet the changes were too small to have any significant impact.

Thus, a brief literature review reveals the complexity of the issue, as no consensus seems to be evolving regarding the impact of the reforms on the small scale industrial sector at the regional level. The present study is an endeavor in this direction and tries to enrich the existing void in literature on measuring technical efficiency and its decomposition into managerial and scale efficiency in Punjab and Haryana.

To achieve the desired objective, the paper has been divided into four sections, including the present introduction. Section-II deals with the background of the study. Section-III concentrates on database and methodological issues, whereas, in Section-IV the 
empirical results are discussed. Section-V concludes the discussion along with offering policy implications.

\section{Background of the Study}

Both Punjab and Haryana are agrarian states and contribute 40 percent of the total agriculture production in India. About 75 percent of the total population of these states directly or indirectly depends on agriculture for their livelihood. Punjab and Haryana are self-sufficient in food production and led the country's Green Revolution in the 1960s; Punjab earned the title of India's 'bread basket'. Both states have done remarkably well in the field of agriculture and are now well on their way to rapid industrialization through the coordinated development of small, medium and large scale industries. Both states have predominantly small-scale industry due to the indomitable spirit and entrepreneurial skills of their peoples.

In Punjab, the number of small scale industrial units is 191,639 , while there are 340 medium and large scale industries involving fixed capital investment of Rs.5502.94 Crore and Rs.23285.58 Crore, respectively. The industries employ around 938,684 workers compared with 199,342 people in the medium and large scale industrial sector (Directorate of Industries Punjab, 2010).

The main industrial centers in Punjab are Ludhiana, Jalandhar, Amritsar, Mandi Gobindgarh, Batala and Mohali. Ludhiana is known for hosiery and readymade garments, sewing machines and parts, auto parts, industrial fasteners, electrical and electronic industries, etc. Jalandhar is famous for manual tools, pipe fitting, valves and cocks, rubber foot wear and shoes, leather products, sports goods, etc. Mandi Gobindgarh, popularly known as the 'steel town of Punjab', has more than 300 steel re-rolling mills, despite being located far away from natural resources. Batala is famous for its production of machines and machine tools. Amritsar is known for food products, chemicals and chemical products, and paper machinery in addition to being famous for textiles. Mohali is presently known as a hub of the electronics and information technology industry (SISI, 2010).

Haryana has 76,639 SSI units, and 1,347 medium and large scale units, involving fixed capital investment of Rs. 4322.02 Crore and Rs.25832.99 Crore, respectively. About 599,651 workers are employed in SSI units compared to 235,555 persons employed in the medium and large scale industrial sector. (Directorate of Industries Haryana, 2010).
Despite several constraints, the small scale industrial sector in Haryana has responded positively and plays an important role by supplementing and complementing large/medium industries. In Faridabad, Ballabhgarh, Sonepat and Gurgaon, this sector has played a vital role in the ancillary development of tractors, automobiles, electrical and electronic goods, manual/machine tools, bicycle accessories, etc. Small scale industry in Yamunanagar, Jagadhri, and Rewari have taken up the manufacture of stainless steel, aluminum and brass utensils, and earned a good name for the state not only in national but international markets as well. The same is the case with small-scale manufacturers of instruments, mixers and grinders in Ambala, agricultural implements in Karnal, textiles and handlooms in Panipat, basmati rice in Karnal, Kurukshetra and Kaithal and sanitary wares in Bahadurgarh. Many of these SSI units are today equipped with modern machines producing quality products at international standards. About 20 percent of the country's total exports of scientific instruments are from the small scale units of Ambala. The SSI units of Yamunanagar meet 60 percent of the demand for ammunitions boxes for the country's defense forces and the units located in Panipat supply 75 percent of the total requirement of woolen blankets to the Indian army (SISI, 2010).

The SSI sector plays a crucial role in promoting the inclusive growth of developing countries owing to low capital intensity, high potential for employment generation, equal distribution of income and exploitation of locally available resources. Therefore, it is not surprising that since independence, the government has been following a strategy for emphasizing the growth of the small scale sector as an agent for transforming the agrarian economy into a modern industrialized one.

\section{Data Base and Methodology}

It is evident from the survey of literature on measuring technical efficiency using data envelopment analysis (DEA) that for obtaining DEA efficiency scores a well defined set of output and input variables is necessary (see, Cooper et al. (2007) for details on DEA models). In the present study, we considered only one output (gross output at constant prices) and two inputs (gross fixed capital at constant prices and number of employees). 


\subsection{Database and Construction of Input / Output Variables}

The present study is confined to the period from 197172 to 2006-07. The choice of terminal year is governed by the availability of the latest data from the Ministry of Statistics and Program Implementation (MOSPI). All monetary data have been deflated by using appropriate price deflators. The gross output figures at constant prices have been utilized as an index of output. Following Goldar (1986), we preferred the use of 'gross output' in place of 'net output' because depreciation charges in the Indian industries are known to be highly arbitrary and fixed by the income tax authorities, and hence seldom represent true/actual capital consumption.

The gross fixed capital stock has been utilized as a measure of capital input. The standard practice of the perpetual inventory method has been followed here to generate the series of gross fixed capital stock at constant prices. This requires a gross investment series, an asset price deflator, a depreciation rate, and a benchmark capital stock. We followed the procedure adopted by Martin and Warr (1990), Austria and Martin (1995) and Wu (1997) for getting an estimate of the initial value of capital stock. This procedure involves the following steps:

Step 1: Deflating the current price figures of the fixed investment of the SSI in India at constant prices using 'Price index of machinery and machine tools', given by using the relationship:

$$
\mathrm{I}_{\mathrm{t}}=\mathrm{GF} \mathrm{I}_{\mathrm{t}} / \mathrm{P}_{\mathrm{t}}
$$

Where, $\mathrm{GFI}_{\mathrm{t}}=$ Fixed Investment at current prices in the year $t$; and

$\mathrm{P}_{\mathrm{t}}=$ Price index of machinery and machine tools in the year $t$.

Step 2: The logarithm of gross real investment was first regressed against a time trend to obtain its average growth rate $\omega$ and a trend value of investment at the beginning of the same i.e., $l_{0}$.

Step 3: Making the conventional assumption that the capital stock grows at a steady state at time $t_{0}$ the value of capital stock for initial year $\left(\mathrm{K}_{0}\right)$ has been then estimated as:

$$
K_{0}=\frac{I_{0}}{\omega+\delta}
$$

Where, $K_{0}=$ Gross value of initial capital stock; $\omega=$ Estimated growth rate of investment; and $\delta=$ Annual rate of discarding of capital. In the present analysis, we have taken the annual rate of discarding of capital to equal 5 percent.

Step 4: After obtaining the estimate of fixed capital for the benchmark year, the following equation has been used for the measurement of gross fixed capital series at 1981-82 prices:

$$
\mathrm{K}_{\mathrm{t}}=\mathrm{K}_{\mathrm{t}-1}+\mathrm{I}_{\mathrm{t}}-\delta \mathrm{K}_{\mathrm{t}-1}
$$

Where, $K_{t}=$ Gross fixed capital at 1981-82 prices by the end of year $t ; I_{t}=$ Gross real investment in fixed capital during the year $t$; and $\delta=$ Annual rate of discarding of capital.

In the present study, the number of employees consisting of both non-production and production workers has been taken as the measure of the labor market. After obtaining all the outputs and factor inputs, the variables have been divided by the number of SSI units operating in India. The figures of number of SSI units have also been downloaded from the same abovementioned source. Thus, the figures obtained by dividing the output and input variables by number of SSI units will provide Gross Output per SSI unit, Labor per unit and GFC per SSI unit in India.

\subsection{Measurement of Technical Efficiency}

The DEA is a linear (mathematical) programming based method first originated in the literature by Charness, Cooper and Rhodes (1978) as a reformulation of the Farrell's (1957) single-output, single-input radial measure of technical efficiency for the multiple-output, multiple-input case. The subsequent technical development of DEA is extensive, certainly to the point of precluding a survey in this instance. Interested parties are directed to those provided by Charnes, Cooper, Lewin and Seiford (1994). What follows is a general discussion of Seiford and Thrall (1990), Ali and Seiford (1993), DEA, with primary attention directed to model formulation. DEA calibrates the level of technical efficiency on the basis of an estimated discrete piece-wise frontier (or so-called efficiency frontier or best-practice frontier or envelopment surface) made up by a set of Paretoefficient decision-making units (DMUs).

In all instances, these Pareto-efficient DMUs are located on the efficiency frontier, and compared to the others minimize the use of productive resources given the outputs (input-oriented measure), or maximize the output given the input size (output-oriented measure) and are called the "best practice performers" or "reference units" or "per units" within the sample of 
DMUs. These Pareto-efficient DMUs score can surpass. Further, this efficiency frontier provides a yardstick against which to measure the relative efficiency of all other decision-making units (DMUs) that do not lie on the frontier. The DMUs which do not lie on the efficiency frontier are deemed relatively inefficient (i.e. Pareto nonoptimal DMUs) and receive a score between zero and one. The efficiency score of each DMU can be interpreted as the radial distance to the efficiency frontier. In short, DEA forms a non-parametric surface frontier (more formally a piece-wise-linear convex isoquant) over the data points to determine the efficiency of each decisionmaking unit relative to this frontier. It is worth noting here that, in a time-series framework like ours, DMU represents $t^{\text {th }}$ year and the best-practice frontier represents the production structure in best-practice years. The formation of frontier is either based upon constant returns-to-scale (CRS) or variable returns-toscale (VRS) assumptions. The CRS assumption is only appropriate if the small scale industrial sector is operating at optimal scale in all the years under evaluation. When the production operations are non-optimum (i.e. variable returns-to-scale (VRS) prevail), the overall technical efficiency (TE) can be decomposed into pure technical efficiency (PTE) and scale efficiency (SE).

Having illustrated DEA intuitively, we may extend the technique to the multiple-output, multiple-input case. DEA involves the use of linear programming methods to construct a non-parametric piece-wise surface (or frontier) over the data. Efficiency measures are then calculated relative to this surface. Assume there are data $K$ inputs and $M$ outputs for each of $T$ years. For the $t^{\text {th }}$ year, these are represented by the column vectors $x_{t}$ and $y_{t}$, respectively. The $K \times T$ inputs matrix, $\mathrm{X}$, and the $M \times T$ output matrix, $Y$, represent for all $T$ firms. The formulation of LPP to determine technical efficiency can be given as:

$$
\operatorname{Min}_{\theta_{t}^{C R S}, \lambda} \theta_{t}^{C R S}
$$

Subject to $\quad-y_{\mathrm{t}}+\mathrm{Y} \lambda \geq 0$,

$$
\theta_{t}^{C R S} \mathrm{x}_{\mathrm{t}}-\mathrm{X} \lambda \geq 0,
$$

Where $\theta_{t}^{C R S}$ is a TE measure of the $t^{\text {th }}$ period under CRS and $\lambda$ is a $T \times 1$ vector of constants. A separate linear programming (LP) problem is solved to obtain the TE score for each of the T years in the sample. If $\theta^{C R S}=1$, the performance of the small scale industrial sector in the given year is on the frontier and is technically efficient under CRS. However, if $\theta^{C R S}<1$, then there exists some inefficiencies in the production process of the given year.

The CRS DEA model detailed above provides the overall technical efficiency (OTE) and is only appropriate when all firms are operating at an optimal scale. Factors that may cause a year to be not operating at an optimal scale include imperfect competition, constraints on finance, etc. The measure of technical efficiency detailed in (2) also assumes that many scaled-up and scaled-down versions of the input combinations are also included in the production possibility set. The use of CRS specification when not all firms are operating at the optimal scale results in measures of TE which are confounded by scale efficiencies (SE). The use of the variable returns-to-scale (VRS) permits the calculation of TE devoid of these SE effects.

The CRS linear programming problem can be easily modified to account for VRS by adding the convexity constraint: $T 1^{\prime} \lambda=1$ to the model (2) to provide (see Banker et al. (1984)):

$$
\min _{\theta_{t}^{V R S}, \lambda} \theta_{t}^{V R S}
$$

Subject to

$$
\begin{aligned}
& -\mathrm{y}_{\mathrm{t}}+\mathrm{Y} \lambda \geq 0, \\
& \theta_{t}^{V R S} \mathrm{x}_{\mathrm{t}}-\mathrm{X} \lambda \geq 0, \\
& \mathrm{~T} 1^{\prime} \lambda=1 \\
& \lambda \geq 0,
\end{aligned}
$$

Where $\theta_{t}^{V R S}$ is an efficiency measure (popularly known as pure technical efficiency (PTE) of the $t^{\text {th }}$ year under VRS and $\mathrm{T} 1$ is a $T \times 1$ vector of one.

This approach forms a convex hull of intersecting planes which envelope the data points more tightly than the CRS conical hull and thus provides pure technical efficiency scores ( $\theta^{V R S}$ ), which are greater than or equal to technical efficiency scores under CRS ( $\theta^{V R S}$ ). Note that the convexity constraint $\left(T 1^{\prime} \lambda=1\right)$, essentially ensures that an inefficient year is only "benchmarked" against years of a similar size output. That is, the projected point (for that firm) on the DEA frontier will be a convex combination of observed years' performances. This convexity restriction is not imposed in the CRS case. Hence, in a CRS DEA model, a given year's performance may be benchmarked against years that are substantially larger (smaller) than it. In this instance the $\lambda$-weights will sum to a value less than (or greater than) one.

Recall that overall technical efficiency (TE) can be divided into pure technical (PTE) and scale efficiency (SE). 
A measure of scale efficiency (SE) of the $t^{\text {th }}$ year can be obtained as:

$$
S E_{t}=\frac{\theta_{t}^{C R S}}{\theta_{t}^{V R S}}
$$

Where SE $=1$ indicates scale efficiency or CRS and SE $<1$ indicates scale inefficiency.

One shortcoming of this measure of scale efficiency is that the value does not indicate whether the DMU is operating in an area of increasing or decreasing returnsto-scale. The latter issue can be determined by running an additional DEA problem with non-increasing returns-toscale (NIRS) imposed. This is done by altering the DEA model ( 1 ) by substituting the $T 1^{\prime} \lambda=1$ restriction with $T 1^{\prime} \lambda$ $\leq 1$, to provide:

$$
\operatorname{Min} \theta_{t}^{N I R S}
$$

Subject to

$$
\begin{aligned}
& -\mathrm{y}_{\mathrm{t}}+\mathrm{Y} \lambda \geq 0, \\
& \theta_{t}^{N I R S} \mathrm{x}_{\mathrm{t}}-\mathrm{X} \lambda \geq 0, \\
& \mathrm{~T} 1^{\prime} \lambda=1 \\
& \lambda \geq 0,
\end{aligned}
$$

Where $\theta_{t}^{N I R S}$ is an efficiency measure of the $\mathrm{t}^{\text {th }}$ year under NIRS and T1 is an $T \times 1$ vector of ones. The nature of the scale inefficiencies (i.e. due to increasing or decreasing returns-to-scale) for a particular DMU can be determined by seeing whether $\theta^{N I R S}$ is equal to $\theta^{V R S}$. If $\theta^{\text {NIRS }} \neq \theta^{\text {VRS }}$ then decreasing returns to scale apply.

\section{Empirical Results}

Table 1 depicts shows that small scale industries in India are operating at low levels of technical efficiency, 56.4 percent during the year 2006-07. Thus the level of inefficiency amounts to 43.6 percent, which means that the output in the small scale sector can be augmented by 43.6 percent, with the same bundle of inputs if the small scale sector of India follows its best practice. Further, it has been observed that level of technical efficiency varies from the minimum efficiency score of 0.324 during the year 1992-93 to the maximum of 1.000 during the year 1989-90 in Indian small scale industries. It is worth mentioning here that the maximum efficiency score is observed during the pre-reform period, whereas in the post-reform period efficiency declined to its minimum.

A comparison of the average technical efficiency during the two sub-periods (pre-reforms and postreforms) revealed that the efficiency in Indian small scale industry has declined at the significant rate of 33.57 percent. Such a significant decline indicates the appalling status of the health of the Indian small scale sector and shows that the reform process has left a significant dent on the efficiency performance of Indian small scale industries.

The reference set analysis provides that during the year 1989-90 the Indian small scale sector utilized its optimum capacity and produced a technically efficient output. This year has appeared 26 times out of 36 years in the reference set. Such a high frequency proves that if the industry follows the same practice which it had followed in 1989-90, the difference between actual output and frontier output can be removed. Hence small scale industry can operate efficiently by minimizing the use of inputs.

Table 2 shows that during the entire study period 20.5 percentage points of 44.9 percent overall technical inefficiency has been contributed by managerial inefficiency (PTE) and the rest is explained by scale inefficiency thus both the managerial and scale factors are equally responsible for the overall technical inefficiency in Indian small scale sector. However, the analysis of the impact of the economic reforms on technical efficiency delineates that during the pre-reform period the overall technical inefficiency had been largely explained by managerial sub per formal. The pre-reform period 24.3 percentage points of the 33.8 percent of the overall technical inefficiency have been explained by pure technical in efficiency and rest is caused by scale factor. Thus management was improper in the small scale industry of India during the pre-reform periods.

However, during the post-reform period the trend has been reversed. During this period 15.6 percentage points of the 58.8 percent of overall technical inefficiency (OTIE) is explained by managerial inefficiency and the remaining high proportion is explained by scale inefficiency. The analysis also reiterates our earlier finding that managerial efficiency improved in the small scale sector during the post-reform period. However. a gargantuan decrease in scale efficiency has led the OTE to fall by more than 60 percent during the post-reform periods. The exposure of the small scale industry in world competiveness after 1991, seen improving, the management of the industry under learning by doing process. However, given managerial irregularities, the industry might not be reaching its scale effectiveness and seems scale inefficient during the second sub-period. 
One of the major objectives is to compare the performance of the small scale industry of Punjab and Haryana with the performance of the small scale industry of India. The comparison of small scale industry of Punjab with that of India reveals that during the entire period of the study small scale industry of Punjab operated with a comparatively high level of efficiency - 82.3 percent, while over the same period the average OTE for Indian small scale industry was 55.1 percent. Hence the small scale industry of Punjab is relatively better off in comparison to the small scale industry of India. Table 3 also reveals that the level of technical inefficiency in the small scale industry of Punjab is 17.6 percent. It simply means that 17.6 percent more outputs can be produced in the small scale industry of Punjab with the same bundle of inputs. The comparison of OTE over the two sub-periods also shows that technical efficiency has been improved by 4.8 percent during the post-reform period. An average efficiency of 0.848 during the post-reform period in comparison to 0.802 percent during the prereform period supports this influence. However the result is the complete inverse of the trends of the Indian small scale industry. For Indian small scale industry, a decline in efficiency over and above 20 percent had been noted during the post-reform period.

Table 4 analyses components of the technical efficiency of the small scale industrial sector in Punjab. It can be observed from the table that 9.2 percentage points of the 17.7 percent OTE were contributed by managerial efficiency and approximately an equal amount of OTE can be explained by scale efficiency. Thus both PTE and SE are equally responsible factors for OTE in the small scale industry of Punjab. However, to explore the factors responsible for an increase in OTE during the post-reform periods we analyze the change in PTE and SE over the two sub-periods of time. The analyses of average PTE and SE scores over the two sub-periods reveal that PTE has increased sustainably from 0.858 in the prereform period to 0.971 during the post-reform period, whereas decline in scale efficiency has been observed from 0.937 during the pre-reform periods to 0.874 during the post-reform period. Thus, a substantial increase in managerial efficiency i.e., (PTE) has been observed to be the driving force behind the increase in overall technical efficiency. During the second sub-period the analysis of RTS in the small scale industry of Punjab reveals that from 1983-84 onwards increasing returns to scale are present, and thus modernization and the proper utilization of technology is required to mitigate technical inefficiency in the small scale industry of Punjab.

The analysis of the level of technical efficiency in the small scale industrial sector of Haryana shows that there exists on average 47 percent technical inefficiency in the small scale industry of Haryana. This amount of inefficiency is highest among the average technical efficiency in the small scale industry of all of India as well as of Punjab. It is worth mentioning that 47 percent output can be increased in the small scale industry of Haryana with constant input bundles. In the lines of the SSI of all of India the technical inefficiency during the post-reform periods has increased in the SSI of Haryana contrary to the reduction in technical inefficiency during the post-reform periods in the state of Punjab. A decline in technical efficiency from 0.687 to 0.334 supports our inference; furthermore, during the year 1981-82 the SSI of Haryana was observed to be operating on the best practice frontier; also during this period management in the SSI was proper along with industry operation at the most desired scale size. However, the lowest efficiency, 16.4 percent, was observed during the year 2001-2002.

Analysis of the causes of technical inefficiency in the SSI of Haryana shows that both managerial inefficiency and scale inefficiency equally contribute to overall technical inefficiency in the SSI of Haryana. About 24.10 percent of observed overall technical inefficiency in the SSI of Haryana was contributed by pure technical inefficiency, while the remainder is caused by scale inefficiency. Further, the decline in managerial efficiency (PTE) is a major factor responsible for the decline in the overall technical efficiency of SSI in Haryana during the post-reform period in comparison to pre-reform periods; moreover, the decline in scale efficiency is serious enough and cannot be ignored, as the PTE declined from 0.890 to 0.595 alongside scale efficiency, from 0.771 to 0.645 , during the post-reform in comparison to the pre-reform period.

The visualization of return to scale parameters represents the existence of increasing returns to scale since from 1982-83 onwards. Thus modernization of the SSI of Haryana can help it to operate on an optimum scale size of production. These results are the lines of return to scale observed for the SSI of India, as well as that of Punjab. In sum, we can conclude that the Indian SSI operates with a huge level of technical inefficiency, and with the exception of Punjab the reforms process has adversely affected the technical efficiency both at the all India level and in the state of Haryana. Thus, given the 
existence of increasing returns to scale, steps must be taken to modernize the production process and upgrade technology in the small scale industrial sector at the national and regional levels.

\section{Summary, Conclusions and Policy Implications}

The present research paper endeavors to analyze the performance of the small scale industrial (SSI) sectors of Punjab and Haryana, and compare the performance of these two states with the small scale industrial sector of India as a whole. Using the time series data over the period from 1972-73 to 2006-07, technical efficiency scores have been calculated using the technique of data envelopment analysis. The analysis reveals that there exists 0.824 percent and 0.530 percent technical efficiency in the small scale industrial sectors of Punjab and Haryana, respectively. However, at the aggregated All-India level, a technical efficiency score of 0.564 has been observed. Thus, the small scale industrial sectors of Punjab and Haryana are operating with 17.6 and 47.0 percent levels of technical inefficiency, respectively. Also, the technical inefficiency level observed for the Indian small scale industrial sector is 43.60 percent. Hence, the small scale industrial sector of Punjab is comparatively more efficient than Haryana and All-India.

The analysis of the impact of economic reforms on the technical efficiency of small scale industrial sectors of AllIndia and the aforementioned states reveals that the reform process has adversely affected both managerial and scale efficiencies of Haryana, while an improvement in managerial efficiency has been observed in the small scale industrial sectors of Punjab and All-India. The empirical analysis showed that in the post-reform period both at the All-India level and in Haryana the technical inefficiency score is increasing, whereas in Punjab it is decreasing.

The decomposition of the technical efficiency scores in managerial and scale efficiency components shows that both of these two components are equally responsible for the observed technical inefficiency in the small scale sectors of All-India in general and at the regional level in particular. The analysis of returns-to-scale confirms the existence of decreasing returns-to-scale in the SSI sector of All-India, whereas increasing returns-toscale have been observed for both of the states under evaluation. Thus, a policy of downsizing is recommended for the India SSI sector, whereas the states of Punjab and Haryana appear to be the exceptions, with increasing returns-to-scale. In both of these states, an increase in the production scale is recommended as technically efficient in the era of liberalization. $[$. 


\begin{tabular}{|c|c|c|c|}
\hline Year & $\begin{array}{l}\text { Overall Technical } \\
\text { Efficiency }\end{array}$ & $\begin{array}{c}\text { Technical } \\
\text { Inefficiency }\end{array}$ & $\begin{array}{c}\text { Reference set } \\
\text { (Sr. No. of Reference Years) }\end{array}$ \\
\hline 1971-72 & 0.570 & 0.430 & 19,36 \\
\hline $1972-73$ & 0.568 & 0.432 & 36,19 \\
\hline 1973-74 & 0.549 & 0.451 & 36,19 \\
\hline 1974-75 & 0.588 & 0.412 & 36,19 \\
\hline $1975-76$ & 0.537 & 0.463 & 36,19 \\
\hline 1976-77 & 0.564 & 0.436 & 36,19 \\
\hline 1977-78 & 0.588 & 0.412 & 36,19 \\
\hline 1978-79 & 0.523 & 0.477 & 19,36 \\
\hline 1979-80 & 0.680 & 0.320 & 36,19 \\
\hline 1980-81 & 0.713 & 0.287 & 36,19 \\
\hline 1981-82 & 0.662 & 0.338 & 36,19 \\
\hline $1982-83$ & 0.618 & 0.382 & 36,19 \\
\hline 1983-84 & 0.657 & 0.343 & 36,19 \\
\hline 1984-85 & 0.693 & 0.307 & 36,19 \\
\hline 1985-86 & 0.740 & 0.260 & 36,19 \\
\hline 1986-87 & 0.793 & 0.207 & 36,19 \\
\hline 1987-88 & 0.857 & 0.143 & 36,19 \\
\hline 1988-89 & 0.915 & 0.085 & 36,19 \\
\hline $1989-90$ & 1.000 & 0000 & 26 appearances in reference set \\
\hline 1990-91 & 0.419 & 0.581 & $20^{*}(12$ appearances in reference set) \\
\hline 1991-92 & 0.371 & 0.629 & $19,20,34$ \\
\hline $1992-93$ & 0.324 & 0.676 & $19,20,34$ \\
\hline 1993-94 & 0.330 & 0.670 & $19,20,34$ \\
\hline 1994-95 & 0.359 & 0.641 & $19,20,34$ \\
\hline $1995-96$ & 0.373 & 0.627 & $19,20,34$ \\
\hline 1996-97 & 0.377 & 0.623 & $19,20,34$ \\
\hline 1997-98 & 0.388 & 0.612 & 20,34 \\
\hline 1998-99 & 0.404 & 0.596 & 36,19 \\
\hline 1999-00 & 0.408 & 0.592 & 20,34 \\
\hline 2000-01 & 0.424 & 0.576 & 20,34 \\
\hline 2001-02 & 0.409 & 0.591 & 20,34 \\
\hline $2002-03$ & 0.422 & 0.578 & 20,34 \\
\hline 2003-04 & 0.453 & 0.547 & 20,34 \\
\hline 2004-05 & 0.486 & 0.514 & $34^{*}(12$ appearances in reference set) \\
\hline 2005-06 & 0.507 & 0.493 & 19,36 \\
\hline 2006-07 & 0.564 & 0.436 & $36^{*}(20$ appearances in reference set $)$ \\
\hline Entire Period & 0.551 & 0.449 & \\
\hline Pre-Reforms & 0.662 & 0.338 & \\
\hline Post-Reforms & 0.412 & 0.588 & \\
\hline
\end{tabular}

Notes: i) Technical Inefficiency=1-Overall Technical Efficiency; ii) Reference set reflects the number of years set as benchmark years of production and iii) * represents that although the SSI is technically inefficient under CRS environment the PTE score equal to 1 leads it to appear in the year 1990-91 in the reference set.

Source: Author's Calculations

Table 1: Inter-temporal Variations in Technical Efficiency of Indian Small Scale Industry 


\begin{tabular}{|c|c|c|c|}
\hline Year & $\begin{array}{l}\text { Pure Technical } \\
\text { Efficiency }\end{array}$ & $\begin{array}{c}\text { Scale } \\
\text { Efficiency }\end{array}$ & Returns-to-Scale \\
\hline $1971-72$ & 0.724 & 0.788 & DRTS \\
\hline $1972-73$ & 0.710 & 0.800 & DRTS \\
\hline $1973-74$ & 0.675 & 0.814 & DRTS \\
\hline $1974-75$ & 0.664 & 0.886 & DRTS \\
\hline $1975-76$ & 0.618 & 0.869 & DRTS \\
\hline 1976-77 & 0.650 & 0.869 & DRTS \\
\hline $1977-78$ & 0.661 & 0.889 & DRTS \\
\hline $1978-79$ & 0.615 & 0.850 & DRTS \\
\hline $1979-80$ & 0.779 & 0.874 & DRTS \\
\hline $1980-81$ & 0.806 & 0.885 & DRTS \\
\hline $1981-82$ & 0.732 & 0.905 & DRTS \\
\hline $1982-83$ & 0.665 & 0.928 & DRTS \\
\hline 1983-84 & 0.698 & 0.940 & DRTS \\
\hline $1984-85$ & 0.738 & 0.940 & DRTS \\
\hline $1985-86$ & 0.779 & 0.950 & DRTS \\
\hline $1986-87$ & 0.823 & 0.963 & DRTS \\
\hline $1987-88$ & 0.875 & 0.980 & DRTS \\
\hline $1988-89$ & 0.918 & 0.996 & DRTS \\
\hline $1989-90$ & 1.000 & 1.000 & CRTS \\
\hline $1990-91$ & 1.000 & 0.419 & IRTS \\
\hline 1991-92 & 0.846 & 0.438 & IRTS \\
\hline $1992-93$ & 0.709 & 0.457 & IRTS \\
\hline 1993-94 & 0.706 & 0.467 & IRTS \\
\hline $1994-95$ & 0.749 & 0.479 & IRTS \\
\hline $1995-96$ & 0.778 & 0.479 & IRTS \\
\hline $1996-97$ & 0.782 & 0.482 & IRTS \\
\hline $1997-98$ & 0.811 & 0.479 & IRTS \\
\hline 1998-99 & 0.710 & 0.569 & DRTS \\
\hline 1999-00 & 0.900 & 0.453 & IRTS \\
\hline 2000-01 & 0.924 & 0.459 & IRTS \\
\hline 2001-02 & 0.870 & 0.470 & IRTS \\
\hline 2002-03 & 0.882 & 0.478 & IRTS \\
\hline 2003-04 & 0.935 & 0.484 & IRTS \\
\hline 2004-05 & 1.000 & 0.486 & IRTS \\
\hline $2005-06$ & 0.894 & 0.567 & DRTS \\
\hline $2006-07$ & 1.000 & 0.564 & DRTS \\
\hline Entire-Reforms & 0.795 & 0.704 & --- \\
\hline Pre-Reforms & 0.757 & 0.877 & \\
\hline Post-Reforms & 0.844 & 0.488 & \\
\hline
\end{tabular}

Notes: i) DRTS represents decreasing returns-to-scale; ii) IRTS represents increasing returns-to-scale; and iii) CRTS represents constant returns to scale.

Source: Author's Calculations

Table 2: Inter-Temporal Variations in Managerial and Scale Efficiency and Returns to Scale in Indian Small Scale Industry 


\begin{tabular}{|c|c|c|c|}
\hline Year & $\begin{array}{l}\text { Overall Technical } \\
\text { Efficiency }\end{array}$ & $\begin{array}{l}\text { Technical } \\
\text { Inefficiency }\end{array}$ & $\begin{array}{c}\text { Reference set } \\
\text { (Sr. No. of Reference Years) }\end{array}$ \\
\hline $1971-72$ & 1.000 & 0000 & 1 \\
\hline $1972-73$ & 0.994 & 0.006 & $2 *(9$ appearances in reference set $)$ \\
\hline $1973-74$ & 0.998 & 0.002 & $3 *(0$ appearances in reference set $)$ \\
\hline 1974-75 & 0.868 & 0.132 & 2,36 \\
\hline $1975-76$ & 0.797 & 0.203 & 2,36 \\
\hline $1976-77$ & 0.869 & 0.131 & 2,36 \\
\hline $1977-78$ & 0.869 & 0.131 & 2,36 \\
\hline $1978-79$ & 0.858 & 0.142 & 2,36 \\
\hline $1979-80$ & 0.859 & 0.141 & 2,36 \\
\hline $1980-81$ & 0.760 & 0.240 & 2,36 \\
\hline $1981-82$ & 0.728 & 0.272 & 2,36 \\
\hline $1982-83$ & 0.748 & 0.252 & 2,36 \\
\hline $1983-84$ & 0.785 & 0.215 & 36,28 \\
\hline $1984-85$ & 0.764 & 0.236 & 36,28 \\
\hline $1985-86$ & 0.731 & 0.269 & 36,28 \\
\hline $1986-87$ & 0.718 & 0.282 & 36,28 \\
\hline 1987-88 & 0.695 & 0.305 & 36,28 \\
\hline $1988-89$ & 0.684 & 0.316 & 36,28 \\
\hline $1989-90$ & 0.693 & 0.307 & 28,25 \\
\hline $1990-91$ & 0.686 & 0.314 & 28,25 \\
\hline $1991-92$ & 0.681 & 0.319 & 25,24 \\
\hline $1992-93$ & 0.627 & 0.373 & 22 \\
\hline $1993-94$ & 0.659 & 0.341 & 23 \\
\hline 1994-95 & 0.773 & 0.227 & $24^{*}(1$ appearance in reference set) \\
\hline $1995-96$ & 0.814 & 0.186 & $25^{*}(5$ appearances in reference set $)$ \\
\hline 1996-97 & 0.805 & 0.195 & 28,25 \\
\hline 1997-98 & 0.843 & 0.157 & 28,25 \\
\hline $1998-99$ & 0.902 & 0.098 & $28^{*}(17$ appearances in reference set) \\
\hline 1999-00 & 0.890 & 0.110 & 36,28 \\
\hline 2000-01 & 0.931 & 0.069 & 36,28 \\
\hline 2001-02 & 0.904 & 0.096 & 36,28 \\
\hline $2002-03$ & 0.917 & 0.083 & 36,28 \\
\hline 2003-04 & 0.931 & 0.069 & 36,28 \\
\hline 2004-05 & 0.931 & 0.069 & 36,28 \\
\hline $2005-06$ & 0.957 & 0.043 & 36,28 \\
\hline $2006-07$ & 1.000 & 0000 & $36^{*}(22$ appearances in reference set) \\
\hline Entire Period & 0.823 & 0.176 & \\
\hline Pre-Reforms & 0.802 & 0.195 & \\
\hline Post-Reforms & 0.848 & 0.152 & \\
\hline
\end{tabular}

Notes: i) Technical Inefficiency=1-Overall Technical Efficiency; ii) Reference set reflects the number of years set as benchmark years of production and iii) * represents that although the SSI is technically inefficient under CRS environment the PTE score equal to 1 leads it to appear in the year 1990-91 in the reference set.

Source: Author's Calculations

Table 3: Inter-temporal Variations in Technical Efficiency of Punjab Small Scale Industry 


\begin{tabular}{|c|c|c|c|}
\hline Year & $\begin{array}{c}\text { Pure Technical } \\
\text { Efficiency }\end{array}$ & $\begin{array}{c}\text { Scale } \\
\text { Efficiency }\end{array}$ & Returns-to-Scale \\
\hline 1971-72 & 1.000 & 1.000 & CRTS \\
\hline $1972-73$ & 1.000 & 0.994 & DRTS \\
\hline 1973-74 & 1.000 & 0.998 & DRTS \\
\hline 1974-75 & 0.905 & 0.960 & DRTS \\
\hline $1975-76$ & 0.837 & 0.952 & DRTS \\
\hline 1976-77 & 0.926 & 0.938 & DRTS \\
\hline 1977-78 & 0.945 & 0.920 & DRTS \\
\hline 1978-79 & 0.929 & 0.924 & DRTS \\
\hline 1979-80 & 0.950 & 0.904 & DRTS \\
\hline $1980-81$ & 0.864 & 0.879 & DRTS \\
\hline 1981-82 & 0.779 & 0.934 & DRTS \\
\hline 1982-83 & 0.755 & 0.992 & DRTS \\
\hline 1983-84 & 0.802 & 0.979 & IRTS \\
\hline 1984-85 & 0.799 & 0.956 & IRTS \\
\hline 1985-86 & 0.780 & 0.937 & IRTS \\
\hline $1986-87$ & 0.774 & 0.928 & IRTS \\
\hline 1987-88 & 0.759 & 0.916 & IRTS \\
\hline 1988-89 & 0.754 & 0.906 & IRTS \\
\hline $1989-90$ & 0.790 & 0.877 & IRTS \\
\hline $1990-91$ & 0.815 & 0.842 & IRTS \\
\hline 1991-92 & 0.852 & 0.800 & IRTS \\
\hline 1992-93 & 1.000 & 0.627 & IRTS \\
\hline 1993-94 & 1.000 & 0.659 & IRTS \\
\hline 1994-95 & 1.000 & 0.773 & IRTS \\
\hline 1995-96 & 1.000 & 0.814 & IRTS \\
\hline 1996-97 & 0.960 & 0.838 & IRTS \\
\hline 1997-98 & 0.972 & 0.867 & IRTS \\
\hline 1998-99 & 1.000 & 0.902 & IRTS \\
\hline 1999-00 & 0.970 & 0.917 & IRTS \\
\hline 2000-01 & 0.998 & 0.933 & IRTS \\
\hline 2001-02 & 0.955 & 0.947 & IRTS \\
\hline 2002-03 & 0.956 & 0.960 & IRTS \\
\hline 2003-04 & 0.957 & 0.973 & IRTS \\
\hline 2004-05 & 0.946 & 0.984 & IRTS \\
\hline 2005-06 & 0.964 & 0.992 & IRTS \\
\hline 2006-07 & 1.000 & 1.000 & IRTS \\
\hline Entire- Period & 0.908 & 0.909 & \\
\hline Pre-Reforms & 0.858 & 0.937 & \\
\hline Post-Reforms & 0.971 & 0.874 & \\
\hline
\end{tabular}

Notes: i) DRTS represents decreasing returns-to-scale; ii) IRTS represents increasing returns-to-scale; and iii) CRTS represents constant returns to scale.

Source: Author's Calculations

Table 4: Inter-Temporal Variations in Managerial and Scale Efficiency and Returns to Scale in Punjab Small Scale Industry 


\begin{tabular}{|c|c|c|c|}
\hline Year & $\begin{array}{l}\text { Overall Technical } \\
\text { Efficiency }\end{array}$ & $\begin{array}{l}\text { Technical } \\
\text { Inefficiency }\end{array}$ & $\begin{array}{c}\text { Reference set } \\
\text { (Sr. No. of Reference Years) }\end{array}$ \\
\hline $1971-72$ & 0.493 & 0.507 & 9 \\
\hline $1972-73$ & 0.487 & 0.513 & 9 \\
\hline $1973-74$ & 0.533 & 0.467 & 9 \\
\hline $1974-75$ & 0.627 & 0.373 & 9 \\
\hline $1975-76$ & 0.600 & 0.4 & 9 \\
\hline $1976-77$ & 0.664 & 0.336 & 9 \\
\hline $1977-78$ & 0.744 & 0.256 & 9 \\
\hline $1978-79$ & 0.778 & 0.222 & 9 \\
\hline $1979-80$ & 0.906 & 0.094 & 9 \\
\hline $1980-81$ & 0.929 & 0.071 & 9,11 \\
\hline $1981-82$ & 1.000 & 0.000 & $11^{*}$ (15 appearances in reference set) \\
\hline $1982-83$ & 0.808 & 0.192 & 11,17 \\
\hline $1983-84$ & 0.742 & 0.258 & 11,17 \\
\hline $1984-85$ & 0.704 & 0.296 & 11,17 \\
\hline $1985-86$ & 0.731 & 0.269 & 11,17 \\
\hline $1986-87$ & 0.65 & 0.35 & $11,17,21$ \\
\hline $1987-88$ & 0.642 & 0.358 & $17^{*}(17$ appearances in reference set) \\
\hline $1988-89$ & 0.598 & 0.402 & 27,17 \\
\hline $1989-90$ & 0.563 & 0.437 & 27,17 \\
\hline $1990-91$ & 0.535 & 0.465 & 27,17 \\
\hline $1991-92$ & 0.497 & 0.503 & $21^{*}(8$ appearances in reference set $)$ \\
\hline $1992-93$ & 0.451 & 0.549 & 27,17 \\
\hline 1993-94 & 0.423 & 0.577 & 27,17 \\
\hline 1994-95 & 0.402 & 0.598 & 27,17 \\
\hline $1995-96$ & 0.367 & 0.633 & 17,27 \\
\hline $1996-97$ & 0.348 & 0.652 & 27,17 \\
\hline $1997-98$ & 0.34 & 0.66 & $27^{*}(8$ appearance in reference set) \\
\hline 1998-99 & 0.221 & 0.779 & $21,11,17$ \\
\hline $1999-00$ & 0.181 & 0.819 & 11,21 \\
\hline $2000-01$ & 0.176 & 0.824 & 11,21 \\
\hline 2001-02 & 0.164 & 0.836 & 11,21 \\
\hline $2002-03$ & 0.278 & 0.722 & 11,21 \\
\hline 2003-04 & 0.313 & 0.687 & 11,21 \\
\hline 2004-05 & 0.364 & 0.636 & $17,21,11$ \\
\hline $2005-06$ & 0.403 & 0.597 & 11,17 \\
\hline 2006-07 & 0.41 & 0.59 & 11,17 \\
\hline Entire Period & 0.530 & 0.470 & \\
\hline Pre- reforms & 0.687 & 0.313 & \\
\hline Post-Reforms & 0.334 & 0.666 & \\
\hline
\end{tabular}

Notes: i) Technical Inefficiency=1-Overall Technical Efficiency; ii) Reference set reflects the number of years set as benchmark years of production and iii) * represents that although the SSI is technically inefficient under the CRS environment the PTE score equal to 1 leads to its appearance in the year 1990-91 in the reference set.

Source: Author's Calculations

Table 5: Inter-temporal Variations in Technical Efficiency of Haryana Small Scale Industry 


\begin{tabular}{|c|c|c|c|}
\hline Year & $\begin{array}{c}\text { Pure Technical } \\
\text { Efficiency }\end{array}$ & $\begin{array}{c}\text { Scale } \\
\text { Efficiency }\end{array}$ & Returns-to-Scale \\
\hline $1971-72$ & 0.939 & 0.525 & DRTS \\
\hline $1972-73$ & 0.728 & 0.669 & DRTS \\
\hline $1973-74$ & 0.729 & 0.731 & DRTS \\
\hline $1974-75$ & 0.720 & 0.871 & DRTS \\
\hline $1975-76$ & 0.713 & 0.842 & DRTS \\
\hline $1976-77$ & 0.807 & 0.823 & DRTS \\
\hline $1977-78$ & 0.876 & 0.850 & DRTS \\
\hline $1978-79$ & 0.920 & 0.846 & DRTS \\
\hline $1979-80$ & 1.000 & 0.906 & DRTS \\
\hline $1980-81$ & 0.990 & 0.939 & DRTS \\
\hline $1981-82$ & 1.000 & 1.000 & CRTS \\
\hline $1982-83$ & 0.896 & 0.902 & IRTS \\
\hline $1983-84$ & 0.897 & 0.828 & IRTS \\
\hline $1984-85$ & 0.902 & 0.780 & IRTS \\
\hline $1985-86$ & 0.988 & 0.739 & IRTS \\
\hline $1986-87$ & 0.956 & 0.680 & IRTS \\
\hline $1987-88$ & 1.000 & 0.642 & IRTS \\
\hline $1988-89$ & 0.942 & 0.635 & IRTS \\
\hline $1989-90$ & 0.908 & 0.620 & IRTS \\
\hline $1990-91$ & 0.896 & 0.597 & IRTS \\
\hline $1991-92$ & 1.000 & 0.497 & IRTS \\
\hline $1992-93$ & 0.859 & 0.525 & IRTS \\
\hline $1993-94$ & 0.869 & 0.486 & IRTS \\
\hline $1994-95$ & 0.898 & 0.447 & IRTS \\
\hline $1995-96$ & 0.902 & 0.407 & IRTS \\
\hline 1996-97 & 0.936 & 0.372 & IRTS \\
\hline $1997-98$ & 1.000 & 0.340 & IRTS \\
\hline 1998-99 & 0.290 & 0.762 & IRTS \\
\hline 1999-00 & 0.246 & 0.737 & IRTS \\
\hline $2000-01$ & 0.238 & 0.737 & IRTS \\
\hline 2001-02 & 0.222 & 0.737 & IRTS \\
\hline $2002-03$ & 0.368 & 0.755 & IRTS \\
\hline 2003-04 & 0.391 & 0.800 & IRTS \\
\hline 2004-05 & 0.408 & 0.892 & IRTS \\
\hline $2005-06$ & 0.439 & 0.918 & IRTS \\
\hline $2006-07$ & 0.455 & 0.901 & IRTS \\
\hline Entire-Period & 0.759 & 0.715 & \\
\hline Pre-Reforms & 0.890 & 0.771 & \\
\hline Post-Reforms & 0.595 & 0.645 & \\
\hline
\end{tabular}

Notes: i) DRTS represents decreasing returns-to-scale; ii) IRTS represents increasing returns-to-scale; and iii) CRTS represents constant returns to scale.

Source: Author's Calculations

Table 6: Inter-Temporal Variations in Managerial and Scale Efficiency and Returns to Scale in Haryana Small Scale Industry 


\section{References}

Ahluwalia, I. J. (2006), "Trade Liberalisation and Industrial Performance A Disaggregated View of Indian Manufacturing in the 1990" in Tendulkar, Mitra, Narayanan and Das (ed.), India: Industrialisation in a Reforming Economy: Essay for K.L. Krishna (New Delhi Academic Foundation), pp 71-304.

Ali, A. I. and Seiford, L. M. (1993), "Computational Accuracy and Infinitesimals in Data Envelopment Analysis", INFOR: Information System and Operations Research, Vol. 31, No. 4, pp 290-297.

Annual Report (2010), Department of Industrial Policy and Promotion, Ministry of Commerce and Industry, Government of India. .

Austria, M.S. and Martin, W. (1995), "Macro-economic Instability and Growth in the Philippines, 1950-87: A Dynamic Approach", The Singapore Economic Review, Vol. 40, No.1, pp 65-81.

Bhavani, T. (1991), "Technical Efficiency in Indian Modern Small Scale Sector: An Application of a Frontier Production Function," Indian Economic Review, Vol. 26, No. 2, pp 149-166.

Charnes, A., Cooper, W.W., Lewin, A. Y. and Seiford, L. M. (eds.) (1994), Data Envelopment Analysis: Theory, Methodology and Applications, Kluwer Academic Publishers, Boston.

Charnes, A., Cooper, W.W. and Rhodes, E. (1978), "Measuring the Efficiency of Decision Making Units", European Journal of Operational Research, Vol.2, No. 6, pp 429-444.

Chaudhuri, S. (2002), "Economic Reforms and Industrial Structure in India", Economic and Political Weekly, Vol.37, No.2, pp 155-162.

Cooper et al. (2007) Data Envelopment Analysis A Comprehensive Text with Models, Applications, References and DEA-Solver Software. Second Edition, Springer.

Director of Industries and Commerce, Government of Haryana.

Director of Industries and Commerce, Government of Punjab.

Economic Survey (2011), Department of Industrial Policy and Promotion, Ministry of Commerce and Industry, Government of India.

Farrell, M. J. (1957), "The Measurement of Productive Efficiency", Journal of the Royal Statistical Society, Series A, Vol. 120, No. 3, pp 253281.

Goldar, B. (1985), "Unit Size and Economic Efficiency in the Small Scale Washing Soap Industry in India", Artha Vijnana, Vol. 27, No.1, pp 21-40.

Goldar, B.N. (1986), Productivity Growth in Indian Industry, Allied Publishers, New Delhi.

Joshi, V. and I.M.D. Little (1996), India's Economic Reforms 1991-2001, Delhi: Oxford University Press.

Lok Sabha (2009), Starred Question No. 171, Dec 1.

Martin, W. and Warr, G. (1990), The Declining Economic Importance of Agriculture, Invited paper to the $34^{\text {th }}$ Annual Conference of the Australian Agricultural Economic Society, Brisbane, Feb. 12-15.

Mehta, S. (2011), "Economic Reforms, Technological Intensity and Industrial Development in India", Economic and Political Weekly, Vol. 46, No. 17 , pp 60-68.

Nagaraj, R. (1997), "What Has Happened Since 1991? Assessment of India's Economic Reforms", Economic and Political Weekly, Vol. 32, No. 44, pp 2859-79.

Nagaraj, R. (2003), "Industrial Policy and Performance Since 1980 Which Way Now?", Economic and Political Weekly, Vol. 38, No. 35, pp 3707-15.
Nikaido, Y. (2004), "Technical Efficiency of Small Scale Industry: Application of the Stochastic Production Frontier Model," Economic and Political Weekly, Vol. 39, No. 6, pp 592-597.

Reserve Bank of India (2011): Handbook of Statistics on Indian Economy.

Seiford, L.M. and Thrall, R.M. (1990), "Recent Developments in DEA: The Mathematical Programming Approach to Frontier Analysis", Journal of Econometrics, Vol. 46, No.1-2, pp 7-38.

Singh, N. (2008), "Services-led Industrialisation in India: Assessment and Lessons" in O'Connor and M Kjollerstrom (ed.), Industrial Development for The $21^{\text {st }}$ Century (Hyderabad: Orient Longman, Zed Books and United Nations), pp 235-94.

Sivalinagam, T. (2008), "A Study on The Performance of Micro and Small Enterprises in Tamilnadu", SEDME, Vol.35, No. 4, pp 61-71.

Suresh, K. (2009), "Impact of Economic Reforms on the Growth Performance of the Small Scale Industrial Sector in India" SEDME, Vol. 36, No. 2, pp 34-51.

Wu, Y. (1997), Productivity and Efficiency: Evidence from Chinese Regional Economies, Discussion Paper. 97-118, Department of Economics, University of Western Australia and Australia. 